\title{
Prevalence of hypoxemia $\&$ its determinates in children with Acute Lower Respiratory infection
}

\author{
Malik $\mathbf{S}^{1}$, Gohiya $\mathbf{P}^{2}$, Sisodia $\mathbf{P}^{3}$ \\ ${ }^{1}$ Dr Shikha Malik, Associate Professor, Department of Pediatrics, Gandhi Medical College, Bhopal, MP, India, ${ }^{2}$ Dr \\ Poorva Gohiya, Assistant Professor, Department of Pediatrics, Gandhi Medical College, Bhopal, MP, India, ${ }^{3}$ Dr Pragati \\ Sisodia, Senior Resident, Department of Pediatrics, Ajmer Medical College, Ajmer, Rajasthan, India
}

Address for Correspondence: Poorva Gohiya, Assistant Professor, Department of Pediatrics, Gandhi Medical College, Bhopal, MP, India. E mail id : gohiyapoorva@gmail .com

\begin{abstract}
Introduction: Acute lower respiratory tract infections (LRTIs), most commonly pneumonia, are one of the major reasons for which children are brought to the hospitals. Effective reduction of mortality due to pneumonia is possible if children suffering from pneumonia are treated appropriately and promptly. Hypoxemia is the most serious manifestation and strong risk factor for mortality among children with acute lower respiratory tract infections. Early detection and treatment of hypoxemia is important in the management of these children. So in our study, we tried to determine prevalence of hypoxemia in children with acute respiratory tract infections. Methods: It was a prospective cross sectional study on 150 children aged 2 months- 60 months with acute respiratory symptoms ( $<14$ days). The children who fulfilled the inclusion criteria were evaluated and examined thoroughly and their data was recorded in a pretested proforma. Statistical analysis was done with IBM SPSS 18. Results: Present study revealed prevalence of hypoxemia to be $35.3 \%$ with no significant correlation of age. Conclusion: Hypoxemia is present in almost one third of $<5$ children admitted with acute LRTIs and it is significantly associated with immediate outcome. Therefore sufficient measures should be employed to detect and manage hypoxemia.
\end{abstract}

Keywords: Hypoxemia, Pulse Oxymeter, Pneumonia, Hemoglobin.

\section{Introduction}

Acute respiratory tract infections are among the major causes of preventable morbidity and mortality worldwide, with most of the deaths occurring among below five years children in developing countries [1]. WHO estimates that pneumonia is the leading cause of death in children under five years of age, killing over 2 million of children annually, accounting for about $20 \%$ of deaths in children under 5 years $[2,3]$.

Acute respiratory tract infections are important cause of morbidity in children, responsible for about $30-50 \%$ of visits to health facilities and for $20-40 \%$ of admissions to the hospitals. In India acute respiratory tract infections are one of the major reasons for which children are brought to the hospitals. Effective reduction in mortality due to pneumonia is possible if children suffering from pneumonia are treated

Manuscript received: $14^{\text {th }}$ Oct 2015

Reviewed: $25^{\text {th }}$ Oct 2015

Author Corrected: $7^{\text {th }}$ Nov 2015

Accepted for Publication: $22^{\text {nd }}$ Nov 2015 appropriately and promptly.Hypoxemia is a serious manifestation of severe respiratory illness in children and a risk factor for mortality. As per the studies case fatality rate is inversely related to oxygen saturation [4].

Oxygen therapy improves the outcome with moderate or severe acute respiratory tract infection and in those with hypoxemia, the severity of hypoxemia correlates with outcome. Such an association between hypoxemia and pneumonia suggest that its early detection and treatment are important aspects in the management of children with acute respiratory tract infections.

Pulse oxymetry is a noninvasive and accurate method of measuring oxygen saturation but is expensive, so may not be available in all health care facilities in developing countries like India. So we are dependent on clinical signs to identify hypoxemia. For this reasons various symptoms and signs have been evaluated in many studies, for their ability to predict hypoxemia[4- 
9]. We determined the prevalence of hypoxemia in children with acute respiratory tract infection admitted in pediatrics emergency department of a teaching institute so as to ascertain proportion of children who might get benefited by oxygen therapy before or during referral.

\section{Material and Method}

Study Design: Prospective cross sectional study

Place of study: Department of Pediatrics, of a medical college in central India.

Study Period: One year.

\section{Inclusion criteria}

1. Children aged 2 to 60 months with respiratory symptoms of $<14$ days duration.

2. Children whose parental consent was obtained for inclusion in study.

\section{Exclusion criteria}

1. Children having chronic respiratory diseases as asthma ,bronchieactasis .

2. Children with congenital heart disease.
3. Children who were referred after cardio pulmonary resuscitation.

4. Children whose parental consent could not be obtained.

At admission, presenting complains with duration were recorded from the caregiver of the child in the pretested clinical record, based on F-IMNCI program.

Clinical examination was done with emphasis on respiratory signs. Oxygen saturation was measured at finger or toe with LOTUS-500 pulse oximeter while the patient was breathing room air. Cut off value of oxygen saturation $<95 \%$ was decided for diagnosis of hypoxemia $[10,11]$.

Study subjects were further classified in to diagnostic categories of pneumonia, acute bronchiolitis, croup, pleural effusion, acute asthma or WALRI (Wheeze Associated Respiratory Tract Infections).

Patients with pneumonia were classified in to very severe pneumonia, severe pneumonia and pneumonia as per the F-IMNCI classification [12]. Investigations done were hemoglobin, complete blood counts, arterial blood gas analysis, chest x-ray.

\section{Observations}

The study showed that out of 150 children included in the study, majority of patients were in the age group of 2-12 months (table 1). The mean age of these children was $12.29 \pm 13.90$ with variance of $193.3458 .54 \%$ of patients were male and $46 \%$ were females.

The common presenting symptoms were fever in $84 \%$ children followed by fast breathing $(60 \%)$, irritability $(52 \%)$, inability to drink(38\%), unusual sleepiness(24\%) and convulsion( $2.7 \%$ ).

Fifty eight percent (58\%) patients had hemoglobin( $\mathrm{Hb})$ more than $10 \mathrm{gm} \%$ and rest of the patients had $\mathrm{Hb}$ less than 10 gm $\%$. X-ray chest findings in majority of patients were suggestive of consolidation (55.3\%) followed by hyperinflation $(26 \%)$ [table 2].

Out of the study subjects $64.7 \%$ patients had oxygen saturation of 95-100 and total prevalence of hypoxemia was found to be $35.3 \%$.

Majority of patients (table 3) were diagnosed to have very severe pneumonia (30\%), pneumonia (29\%) and acute bronchiolitis (26\%). On assessing the outcome, 82.7\% patients were discharged after successful treatment, $12.7 \%$ patients left against medical advice and 6 died during treatment, leading to mortality rate of $4 \%$.

The difference in mortality of hypoxemic and non hypoxemic children was statistically significant with $\mathrm{p}<0.001$ (table 4 ).

Present study showed that hypoxemia was present in $36.85 \%$ of infants 2 months to 12 months and $30.7 \%$ of children aged between 13 months to 60 months. Total prevalence of hypoxemia was $35.3 \%$. (figure 1). Age difference was not found significant among hypoxemic and non-hypoxemic group. 
Fig 1: Distribution of oxygen saturation in children with LRTI:

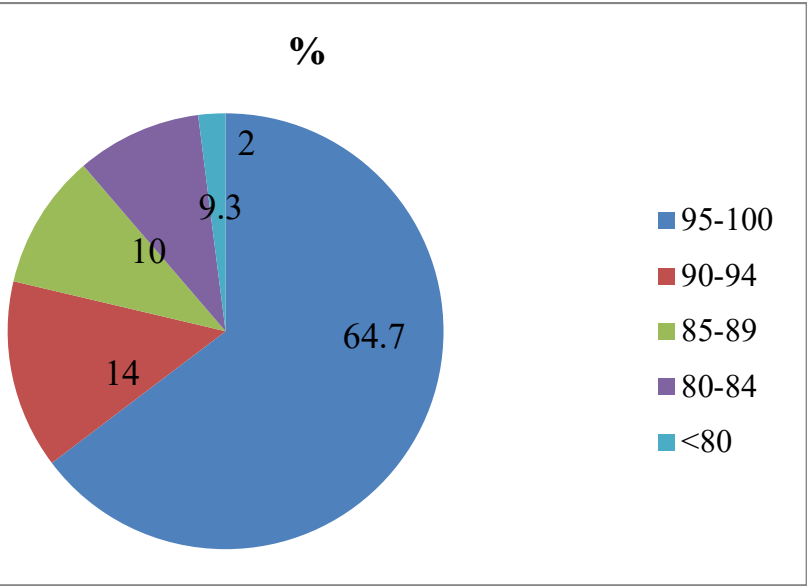

Table-1: Distribution of age in hypoxemic and non hypoxemic children

\begin{tabular}{|c|c|c|c|}
\hline Age in months & $\mathbf{N}$ & Hypoxemic (\%) & Non Hypoxemic (\%) \\
\hline $2-12$ & 111 & $41(36.9)$ & $70(63.1)$ \\
\hline $13-24$ & 24 & $8(33)$ & $16(67)$ \\
\hline $25-36$ & 5 & $1(20)$ & $4(80)$ \\
\hline $37-48$ & 4 & 0 & $4(100)$ \\
\hline $49-60$ & 6 & $3(50)$ & $3(50)$ \\
\hline Total & 150 & 53 & 97 \\
\hline
\end{tabular}

(p value 0.636$)$

Table-2: Investigations and their significance in hypoxemia

\begin{tabular}{|c|c|c|c|c|c|c|}
\hline \multirow{2}{*}{ Investigations } & \multirow{2}{*}{ Parameters } & \multicolumn{2}{|c|}{ hypoxemic } & \multicolumn{2}{|c|}{ Non hypoxemic } & \multirow{2}{*}{$P$ value } \\
\hline & & $\mathrm{n}$ & $\%$ & $\mathrm{n}$ & $\%$ & \\
\hline Hemoglobin & $\mathrm{Hb}<10 \mathrm{gm} \%$ & 33 & 62.26 & 30 & 30.9 & 0.000 \\
\hline \multirow{5}{*}{ X-ray findings } & Consolidation & 34 & 68 & 49 & 50 & \multirow{5}{*}{0.265} \\
\hline & Hyperinflation & 9 & 18 & 30 & 30.9 & \\
\hline & Normal & 4 & 8 & 15 & 15.46 & \\
\hline & Collapse & 2 & 4 & 3 & 3 & \\
\hline & Pleural effusion & 1 & 2 & 0 & 0 & \\
\hline \multirow{2}{*}{ ABGA } & $\mathrm{Ph}<7.35$ & 37 & 78.7 & 13 & 17.5 & 0.000 \\
\hline & $\mathrm{pO} 2<80$ & $31 / 47$ & 65.9 & 3 & 3.6 & 0.005 \\
\hline
\end{tabular}

Table 3: Distribution of diagnosis in hypoxemic and non hypoxemic group

\begin{tabular}{|c|c|c|c|}
\hline Diagnosis & Total & Hypoxemic(\%) & Non -Hypoxemic (\%) \\
\hline Very severe pneumomia & 45 & $33(73)$ & $12(27)$ \\
\hline Severe pneumomia & 11 & $3(27)$ & $8(73)$ \\
\hline Pneumomia & 44 & $2(4.5)$ & $42(95.5)$ \\
\hline Acute bronchiolitis & 40 & $9(22.5)$ & $31(77.5)$ \\
\hline Pleural effusion & 3 & $1(33)$ & $2(67)$ \\
\hline Acute asthma & 3 & $3(100)$ & $2(50)$ \\
\hline Croup & 4 & $2(50)$ & 97 \\
\hline Total & 150 & 53 & 0 \\
\hline
\end{tabular}


Table 4: Distribution of Outcome in hypoxemic and non hypoxemic group

\begin{tabular}{|c|c|c|c|c|}
\hline \multirow{2}{*}{ Outcome } & \multicolumn{2}{|c|}{ Hypoxemic } & N & Non Hypoxemic \\
\cline { 2 - 5 } & $\mathbf{N}$ & $\mathbf{\%}$ & 0 & 0 \\
\hline Death & 6 & 11.3 & 9 & 9.27 \\
\hline Lama & 10 & 18.8 & 87 & 89.6 \\
\hline Discharge & 37 & 69.8 & 1 & 1.03 \\
\hline Other & & & \\
\hline
\end{tabular}

$\mathbf{P}<\mathbf{0 . 0 0 1}$

Table depicted that $11.3 \%$ deaths were reported among hypoxemic patients and no death reported in nonhypoxemic group. This was statistically significant.

\section{Discussion}

A plausible gold standard for the presence of severe disease in acute lower respiratory tract infections is the presence of hypoxemia. Treatment guidelines recommend that in a child with pneumonia admitted for inpatient care, pulse oxymetry, a non invasive estimate of arterial oxygen, should be used to guide oxygen therapy $[10,11,13]$.

But due to limited resources as an alternative, recent studies have suggested a range of respiratory and non respiratory signs that predict hypoxemia, thus guiding referral for or administration of oxygen therapy.

In our study 150 children aged between 2 to 60 months presenting with respiratory symptoms were evaluated for the prevalence of hypoxemia.

Our study showed hypoxemia in $36.95 \%$ patients in infants $2-12$ months and $30.7 \%$ of children aged 13 to 60 months. Age difference was not found significant in hypoxemic and non hypoxemic group similar to some previous studies $[16,17]$.

While in a study done by Singhi $\mathrm{S}$ et al in subjects aged 2-59 month, hypoxemia was more frequent (16.1\%) in infants 2-11 months as compared to children 12-59 months with p-value 0.05 . This difference may be due to difference in sample size [16].

The overall prevalence of hypoxemia is $35.3 \%$ in our study while in a study done by Singhi $\mathrm{S}$ et al it was $11.9 \%$ [16]. Rakesh Lodha et al and Supartha et al found $25.7 \%$ and $17.5 \%$.respectively in their studies $[17,18]$.

This variance can be explained by differences in definition of hypoxemia, location (whether in the emergency room, inpatient ward or outpatient clinic) and the altitude where the study was conducted.
The distribution of hypoxemia in various diagnosis groups was assessed. It was found that the prevalence of hypoxemia was $73 \%$ in children with very severe pneumonia, $27 \%$ in severe pneumonia, $22.5 \%$ in bronchiolitis. We found insignificant correlation between various groups and hypoxemia $(p=0.341)$. This is contrary to results from previous studies on hypoxemia in acute (LRTIs). The principal mechanism for hypoxemia of acute respiratory infection is mismatch between ventilation and perfusion in areas of pneumonic consolidation.

Lung compliance decreases leading to increased work required for ventilation. Dehydration from fever and inability to drink, lead to hemoconcentration, peripheral underperfusion and increase metabolic acidosis leading to compensatory hyperventilation, which limits its usefulness in assessing the degree of hypoxemia despite its usefulness in guiding the degree of systemic disturbance.

In the present study there was significant correlation of $\mathrm{Hb}$ less than $10 \mathrm{gm} \%$ with hypoxemia $(\mathrm{p}<0.000)$. On ABGA both low $\mathrm{pH}$ and $\mathrm{pao}_{2}$ was significantly associated with hypoxemia. But x-ray findings were not significantly associated with hypoxemia.

According to our study presence of hypoxemia is predictive of short term mortality, indicating that the detection and treatment of hypoxemia may be crucial part of clinical management of these severely ill children in hospital. Conversely absence of hypoxemia predicts a low risk of death, even in the presence of radiological pneumonia.

This correlated well with the study by Onyango et al where short term mortality was 3-4 times greater in hypoxemic children [1]. 
The clear association of hypoxemia with mortality suggests that the detection and effective treatment of hypoxemia with oxygen are important aspects in the management of critically ill patients.

\section{Conclusion}

Present study revealed prevalence of hypoxemia to be $35.3 \%$ and difference in mean age for hypoxemic and non hypoxemic group was not statistically significant. As almost one third children with pneumonia have hypoxemia ,the availability of oxygen should be ensured at primary health centers located in the most peripheral areas.

This will definitely help in decreasing the mortality occurring due to pneumonia. Mortality rate was $11.3 \%$ in the hypoxemic group which is statistically significant. Thus presence of hypoxemia is predictive of short term mortality, indicating that the detection and treatment of hypoxemia may be a crucial part of clinical management of severely ill children in hospital.

Ethical approval: Obtained from Institutional Ethics Committee (Human Studies)

Funding: No funding sources.

Conflict of Interest: The authors declare no conflict of interest

\section{References}

1. Onyango FE, Steinhoff MC, Wafula EM, Wariua $\mathrm{S}$, Musia J, Kitonyi J. Hypoxaemia in young Kenyan children with acute lower respiratory infection. BMJ. 1993 Mar 6;306(6878):612-5.

2. Bryce J, Boschi-Pinto C, Shibuya K, Black RE; WHO Child Health Epidemiology Reference Group. WHO estimates of the causes of death in children. Lancet. 2005 Mar 26-Apr 1;365(9465):114752.

3. Margolis PA, Ferkol TW, Marsocci S, Super DM, Keyes LL, McNutt R, Harrell FE Jr. Accuracy of the clinical

examination in detecting hypoxemia in infants with resp iratory illness. J Pediatr. 1994 Apr;124(4):552-60.

4. WHO (199),Health situation in the South-East Asia \& Region 1994-1997, Regional office for SEAR, New Delhi.http://www.searo.who.int/entity/health_situation trends/documents/health_situation_sear_1994-1997.pdf
5. Govt. Of India(2011).Annual report to the people on health. Ministry of Health \& Family Welfare, New Delhi.http://mohfw.nic.in/WriteReadData/1892s/696014 4509Annual\%20Report\%20to\%20the\%20People\%20on $\% 20$ Health.pdf

6. Duke T, Blaschke AJ, Sialis S, Bonkowsky JL. Hypoxaemia in acute respiratory and non-respiratory illnesses in neonates and children in a developing country. Arch Dis Child. 2002 Feb;86(2):108-12.

7. Duke T, Mgone J, Frank D. Hypoxaemia in children with severe pneumonia in Papu a New Guinea. Int $J$ Tuberc Lung Dis. 2001 Jun;5(6):511-9.

8. Pocket book of hospital care for children: guidelines for the management of common illnesses with limited resources. 1.Pediatrics 2.Child care 3.Hospitals 4.Child, Hospitalized 5.Developing countries 6.Practice guidelines 7.Manuals I.World Health Organization. ISBN 9241546700 (NLM classification: WS 29)

9. Leon C, Ricardo A, Stephen M, Mary Fran H. Pediatric Advanced Life Support American Heart Association.Pg no-17.ISBN 13978-1-61669-354-1

10. F-MNCI Facility based integrated management of neonatal and childhood illness. Pg no 111-113.

11. Park K. Park's Textbook of Preventive and Social medicine Bhanot,21 ${ }^{\text {st }}$ Edition Pg 156.

12. IMNCI- Integrated management of neonatal and childhood illness by WHO and Ministry of Health \& Family welfare, Government of India.

13. Lozano JM, Duque OR, Buitrago T, Behaine $\mathrm{S}$. Pulse oximetry reference values at high altitude. Arch Dis Child. 1992 Mar;67(3):299-301.

14. Mwaniki MK, Nokes DJ, Ignas J, Munywoki P, Ngama M, Newton CR, Maitland K, Berkley JA. Emergency triage assessment for hypoxaemia in neonates and young children in a Kenyan hospital: an observational study. Bull World Health Organ. 2009 Apr;87(4):263-70.

15. MORRISON B. Anoxia in the acute respiratory infections of childhood; its recognition and treatment. Lancet. 1955 Oct 8;269(6893):737-40. 
16. Singhi S, Deep A, Kaur H. Prevalence \& predictors of hypoxemia in acute respiratory infections presenting to pediatric emergency department. Indian J Crit Care Med 2003;7:118-123.

17. Rakesh Lodha, Prateek Singh Bhaduria, Anoop Verghese Kuttikat, Madhavi Puranik, Saurabh Gupta, Pandey R M , Kabra S.K. Can clinical symptoms and signs accurately predict hypoxemia in children with acute lower respiratory tract infections? Indian Pediatrics 2004;41(7):129-135.

18. Made Supartha, Putu Siadi Purniti, Roni Naning, Ida Bagus Subanada. Clinical predictors of hypoxemia in 1-5 year old children with pneumonia. Paediatr Indones.2010;50:355-60.

\section{How to cite this article?}

Malik S, Gohiya P, Sisodia P. Prevalence of hypoxemia \& its determinates in children with Acute Lower Respiratory infection. Pediatr Rev: Int J Pediatr Res 2015;2(4):94-99.doi:10.17511/ijpr.2015.i04.11 